\title{
Development of a Stability Indicating UPLC-MS/MS Method for Rapid and Reliable Determination of Fenofibrate in Marketed Product (Lypanthyl ${ }^{\circledR}$ 200M) and Human Plasma
}

\author{
Wabaidur $\mathrm{SM}^{1}$, Mohsin $\mathrm{K}^{\star_{2}}$ and Alothman $\mathrm{ZA}^{1}$ \\ ${ }^{1}$ Advanced Materials Research Chair, Department of Chemistry, College of Science, King Saud University, P.O. BOX- \\ 2455, Riyadh 11451, Saudi Arabia \\ ${ }^{2}$ Kayyali Chair for Pharmaceutical Industries, College of Pharmacy, King Saud University, PO.BOX-2457, Ri- \\ yadh-11451, Saudi Arabia
}

${ }^{*}$ Corresponding author: Mohsin K, Kayyali Chair for Pharmaceutical Industries, Department of Pharmaceutics, College of Pharmacy, King Saud University, Po.box-2457, Riyadh-11451, Saudi Arabia, Fax: +966 (1) 4676295, Tel: +966 (1) 4677372, E-mail: mkazi@ksu.edu.sa

Citation: Wabaidur SM, Mohsin K, Alothman ZA (2013) Development of a Stability Indicating UPLC-MS/ MS Method for Rapid and Reliable Determination of Fenofibrate in Marketed Product (Lypanthyl 200M) and Human Plasma. J Pharm Drug Devel 1(1): 102. doi: 10.15744/2348-9782.1.102

Received Date: June 19, 2013 Accepted Date: July 29, 2013 Published Date: August 01, 2013

\begin{abstract}
A reliable, fast, sensitive and selective Ultra Performance Liquid Chromatography-Tandem Mass Spectrometry (UPLC-MS/MS) method has been developed and validated for the determination of fenofibrate in marketed product (Lipanthyl) and human plasma. The chromatographic separation was performed on a reversed-phase Acquity ${ }^{\oplus} \mathrm{BEH} \mathrm{C}_{18}$ column $(1.7 \mu \mathrm{m}$ particle size, $50 \mathrm{~mm} \times 2.1$ $\mathrm{mm}$ ID) with an isocratic elution profile and mobile phase consisting of methanol and water $(80: 20, \%$, v/v). To achieve optimum chromatographic condition the influence of mobile phase composition and flow rate was investigated. The total chromatographic analysis time was as short as $2 \mathrm{~min}$. Detection and quantification of the analyzed drug sample were carried out with a triple quadrupole mass spectrometer using Electrospray Ionization (ESI) operating in positive ionization mode. The data acquisition was performed in Multiple Reactions Monitoring (MRM) mode. The method was validated over a concentration range of 0.5-200ng/ $\mathrm{mL}\left(\mathrm{r}^{2}=0.993, \mathrm{n}=6\right)$. The selectivity, matrix effect, recovery, accuracy, precision, and stabilities were validated for determination of fenofibrate in human plasma. Analytical recoveries of extracted fenofibrate from plasma were more than $92 \%$. The validation results showed that the proposed method was sensitive, economical and less toxic and it could successfully be applied for evaluation of pharmacokinetics of fenofibrate in animals.
\end{abstract}

Keywords: Fenofibrate; UPLC-MS/MS; Lypanthyl 200M; Plasma; Method validation

\section{Introduction}

Fenofibrate (FF) chemically known as 2-[4-(4-chlorobezoyl) phenoxy]-2-methylpropionic acid 1-methylethyl ester is a lipophilic antihyperlipoproteinemic agent [1]. It is a nonelectrolyte with low aqueous solubility $(<3 \mathrm{mg} / \mathrm{mL})$ and fairly high octanol/ water partition coefficient (log P 4.6). Fenofibrate (FF) is a drug of the fibrate class. It is mainly used to reduce cholesterol levels in patients at risk of cardiovascular disease [2]. It also appears to have a beneficial effect on the insulin resistance featured by the metabolic syndrome [3]. Fenofibric acid (2-[4'- (p-chlorobenzoyl) phenoxy]-2methylpropionic acid), the active metabolite of fenofibrate, produces reductions in total cholesterol, Low-Density Lipoprotein (LDL), apolipoprotein B, total triglycerides and triglyceride rich Very-Low-Density Lipoprotein (VLDL) in treated patients. In addition, treatment with FF results in increase in High Density Lipoprotein (HDL) [4] and apoproteins apoAI [5]. Fenofibrate (FF) as generic products has been very available recently to fulfill the demand of the global healthcare market. To maintain product quality, assist in regulatory filing, and design of correct dose regimen for clinical trials, the first and leading clinical investigation is the characterization of human pharmacokinetics for the drugs. Various methods for analysis of FF in pharmaceutical formulations and or in biological fluids have been reported in the literature including Liquid Chromatography (LC) [6-9], LC-Mass Spectrometry (MS) [10,11], voltammetry, polarography $[12,13]$, Spectrophotometry $[14,15]$ and derivative spectrophotometry [16,17].

The UPLC-MS/MS method described in this paper allows the lower limit of quantitation of FF in pharmaceutical tablet and human plasma down to $0.5 \mathrm{ng} / \mathrm{mL}$ which is indicating the high sensitivity of the method. Also the Electrospray Ionization (ESI) source equipped with UPLC-MS/MS system has become an ideal and widely used techniques in characterization and quantitative analysis of pharmaceutical drugs with improved selectivity, sensitivity and efficiency over other conventional methods, such as, Radioimmunoassay 
(RIA), Gas Chromatography/Mass Spectrometry (GC/MS) and Liquid Chromatography (LC) with UV [5]. The key achievement of the current studies is the development of a sensitive method based on UPLC-MS/MS to quantitate the amount of active components such as FF in commercial pharmaceutical dosage formulation and spiked human plasma. The method is simple, rapid, precise, reproducible and highly sensitive in addition with other advantage that the quantitation might be precisely performed without utilizing an internal standard.

\section{Experiment}

\section{Chemicals and Reagent}

Fenofibrate was purchase from Sigma Aldrich Co, St. Louis, MO, USA with $99.8 \%$ purity. HPLC-grade Methanol (MeOH) and Acetonitrile (ACN) were purchased from BDH Laboratory Supplies (BDH Chemicals Ltd., Poole, UK). HPLC-grade water was obtained from distilled water passed through a Milli-Q water purification system (Millipore, Bedford, MA, USA). Human plasma containing Ethylene Diamine Tetra Acetic Acid (EDTA) as anticoagulant was collected in-house which were free from HIV and Hepatitis. All other solvents were used as analytical grade.

\section{Instrumentation}

Liquid chromatography: UPLC analysis were carried out using an Acquity UPLC system (Waters Corp., Milford, MA, USA), equipped with a binary solvent manager and a sample manager. Chromatographic separation was performed using a Waters Acquity ${ }^{\circledast} \mathrm{BEH} \mathrm{C}_{18}$ column, $(1.7 \mu \mathrm{m}$ particle size, $50 \mathrm{~mm}$ $\mathrm{x} 2.1 \mathrm{~mm}$ ID). The column was kept at $30^{\circ} \mathrm{C}$ and the sample manager was maintained at $10^{\circ} \mathrm{C}$. Mobile phase consisted of a mixture of methanol/ water $(80 / 20, \%, v / v)$. The total analysis run time was $2 \mathrm{~min}$. The sample injection volume was $5 \mu \mathrm{L}$ and sample loop was selected as partial loop with needle overfill.

Mass spectrometry: A TQD (triple quadrupole) mass spectrometer from Micromass Company Inc. (Manchester, UK) equipped with Electro Spray Ionization (ESI) source was used to acquire the mass spectral data of the analyzed compound. An Oerlikon rotary pump, model SOGEVAC SV40 BI (Paris, France) was provided the primary vacuum to the mass spectrometer. Ions were measured in positive ESI mode. The optimized specific cone voltage was chosen for the formation of precursor ion and the Multiple Reactions Monitored (MRM) conditions were optimized to obtain the transition precursor ion-product ion and collision energy for the analysis of drugs (Table 1). High-purity nitrogen was used as drying gas as well as nebulising gas produced by a Peak Scientific NM30LA nitrogen generator (Inchinann, UK). High-purity Argon (99.99\%) supplied by Speciality Gas Centre (Jeddah, Saudi Arabia) was used as collision gas. The collision gas flow was set at $0.10 \mathrm{ml} / \mathrm{min}$. Data acquisition was carried out by MassLynx V4.1 software (Micromass, Manchester, Lancashire, UK).

\begin{tabular}{|l|l|l|l|l|l|l|l|}
\hline Analyte & \multicolumn{3}{|c|}{$\begin{array}{r}\text { Precursor ion } \\
(\mathbf{m} / \mathbf{z})\end{array}$} & \multicolumn{2}{l|}{$\begin{array}{l}\text { Quantification } \\
\text { transition }\end{array}$} & \multicolumn{2}{l|}{$\begin{array}{l}\text { Confirmation } \\
\text { transition }\end{array}$} \\
\hline & & $\begin{array}{l}\text { Prod- } \\
\text { uct } \\
\text { ion } \\
\text { in/z) }\end{array}$ & $\begin{array}{l}\text { Cone } \\
\text { volt- } \\
\text { age } \\
(\mathrm{V})\end{array}$ & $\begin{array}{l}\text { Col- } \\
\text { lision } \\
\text { energy } \\
(\mathrm{eV})\end{array}$ & $\begin{array}{l}\text { Prod- } \\
\text { uct } \\
\text { ion } \\
(\mathrm{m} / \mathrm{z})\end{array}$ & $\begin{array}{l}\text { Cone } \\
\text { volt- } \\
\text { age } \\
(\mathrm{V})\end{array}$ & $\begin{array}{l}\text { Collision } \\
\text { energy } \\
(\mathrm{eV})\end{array}$ \\
& & & & & & \\
\hline FF & 361 & 233 & 36 & 20 & 139 & 36 & 38 \\
\hline
\end{tabular}

a Dwell time was $0.025 \mathrm{~s}$; Ionization mode: $\mathrm{ESI}^{+}$

Table 1: Data acquisition parameters of MRM transitions for FF used in UPLC-MS/MS

\section{Preparation of stock solution, calibration standard}

Approximately $1000 \mu \mathrm{g} / \mathrm{mL}$ of stock solution for fenofibrate was prepared using HPLC grade methanol. This solution was diluted to make a series of standard working solutions in the range from $0.10-250 \mathrm{ng} / \mathrm{mL}$. All the working solutions were freshly prepared. All calibration standard solutions of FF were analyzed in duplicate to establish the linearity of the method.

Tablet sample preparation: Ten tablets (Lipanthyl 200mg dose) were weighed using analytical balance and powdered in a mortar. A tablet amount was weighed and transferred to a $100 \mathrm{ml}$ calibrated flask and dissolved with methanol and then stirred and sonicated until the tablet particles dissolved completely. The final solution was diluted to the working range for application of the developed method. After dilution, the samples were filtered through a $0.22 \mu \mathrm{m}$ disposable nylon filter (Bellefonte, PA, USA) into amber glass auto sampler vials for UPLC-MS/MS analysis.

Plasma sample preparation: Liquid-Liquid Extraction (LLE) procedure was used for the extraction of FF from the human plasma. The drug free plasma sample $(0.5 \mathrm{ml})$ was transferred into a series of $15 \mathrm{ml}$ centrifugation tubes. Aliquots of FF standard methanolic solution were added to each tube and vortexed for $3 \mathrm{~min}$, so that the final concentration of the analyte was in the range $0.5-200 \mathrm{ng} / \mathrm{ml}$. Then $5 \mathrm{ml}$ of organic solvent containing ethyl acetate: diethyl ether was added to all tubes and extraction was performed by vortex mixing for 10 $\min$. The tubes were then centrifuged for $10 \mathrm{~min}$ at $5000 \mathrm{rpm}$. Separate $4 \mathrm{ml}$ of organic layer to clean centrifuge tubes and was evaporated to dryness under $\mathrm{N}_{2}$ at $45-50^{\circ} \mathrm{C}$. Dry residues was then dissolved in $200 \mu \mathrm{l}$ of dilluent (methanol containing $0.1 \%$ formic acid), vortexed for $1 \mathrm{~min}$ to reconstitute residues and transferred to an auto sampler vial and injected into the UPLC-MS/MS system.

\section{Matrix effect}

Matrix effect is due to co-elution of some endogenous components present in biological samples. These components may not give a signal in MRM of target analyte, but can certainly decrease or increase the response of the analyte dramatically to affect the sensitivity, accuracy and precision of the method. To evaluate the matrix effect, comparison of chromatographic peak areas of FF present in a sample extract from one single lot to the response of a standard in neat solution were carried out [18]. 


\section{Validation study}

The following method parameters were evaluated in order to validate the quality of the proposed method: linearity, recovery, precision, Limits of Detection (LOD) and Limits of Quantification (LOQ). Linear range of the proposed method was established by analysis of six standard calibration solutions, in duplicate, in the concentration range of $0.5-200.0 \mathrm{ng} / \mathrm{ml}$ of FF. Recoveries were calculated using the slope of the linear regression. The intra and inter-day precision were evaluated by repeating the assay method three times (six replicates each time) on the same day and on three consecutive days (six replicates each day), respectively. Detection and quantification limit were determined by spiked samples based on signal to noise ratio of 3:1 and 10:1, respectively.

\section{Results and Discussion}

\section{Optimization of chromatographic separation conditions}

Method development was begun with the optimization of chromatographic conditions including mobile phase composition and column type. The feasibility of various mixtures of solvents such as methanol with milliQ water and water containing $0.1 \%$ formic acid was tested. Mobile phase comprising of methanol and milliQ water $(80: 20 ; \% \mathrm{v} / \mathrm{v})$ was shown improved signal-to-noise ratio and thus found to be suitable for the chromatographic separation of the analytes. The chromatographic separation of FF using different columns $\left(\mathrm{C}_{8}, \mathrm{C}_{18}\right.$ and amide) was evaluated. The separation with good symmetry was achieved with Acquity UPLC BEH C ${ }_{18}(2.1$ x 50 $\mathrm{mm}, 1.7 \mu \mathrm{m}$ ) column with flow rate of $0.3 \mathrm{ml} / \mathrm{min}$ maintaining the column oven temperature at $30^{\circ} \mathrm{C}$ The major benefits of the UPLC columns, where particle size is $<2.0 \mu \mathrm{m}$, is that the efficiency does not drop even at higher flow rates. Figure 1 shows the chromatograms of FF $(500 \mathrm{ng} / \mathrm{mL})$ standards in MRM mode obtained with the optimal working conditions.

\section{Optimization of ESI-MS/MS conditions}

The Mass spectrometric (ESI-MS/MS) conditions were optimized to achieve the maximum stable response of the parents and the major product ions of the analytes by infusing standards of FF (500ng/mL) in both positive and negative ionization modes. Comparatively better analyte signal was appeared in positive mode rather than negative ionization mode under different MS parameters. Therefore, the optimization was carried out in positive ionization mode and was chosen for mass spectrometric detection. The triple quadrupole used in this work was provided narrow chromatographic peak $(5 \mathrm{~s}$ width). The MS conditions such as capillary voltage (2.0-4.5 $\mathrm{kV})$, cone voltage $(5-110 \mathrm{~V})$, source temperature $\left(100-150^{\circ} \mathrm{C}\right)$, desolvation temperature $\left(200-450^{\circ} \mathrm{C}\right)$ and desolvation gas $(400$ $800 \mathrm{~L} / \mathrm{h}$ ) were tuned to maximize the selectivity and sensitivity for the detection. The optimized MS conditions were, capillary voltage: $3.5 \mathrm{kV}$, cone voltage: $30 \mathrm{~V}$, source temperature: $120^{\circ} \mathrm{C}$, desolvation temperature: $250^{\circ} \mathrm{C}$ desolvation gas flow $500 \mathrm{Lh}^{-1}$ and collision gas flow: $0.1 \mathrm{ml} / \mathrm{min}$. Full scan mass spectra were recorded in order to select the most abundant $\mathrm{m} / \mathrm{z}$ value. The most abundant precursor is $\mathrm{m} / \mathrm{z} 361$ (FF) which is displayed in Figure 2a. MRM with two transitions was acquired while the most sensitive transition was used for quantification and the other one for confirmation analysis Figure $2 \mathrm{~b}$. The Optimized MRM parameters (precursor and product ions, cone voltages and collision energies) are shown in Table 1.

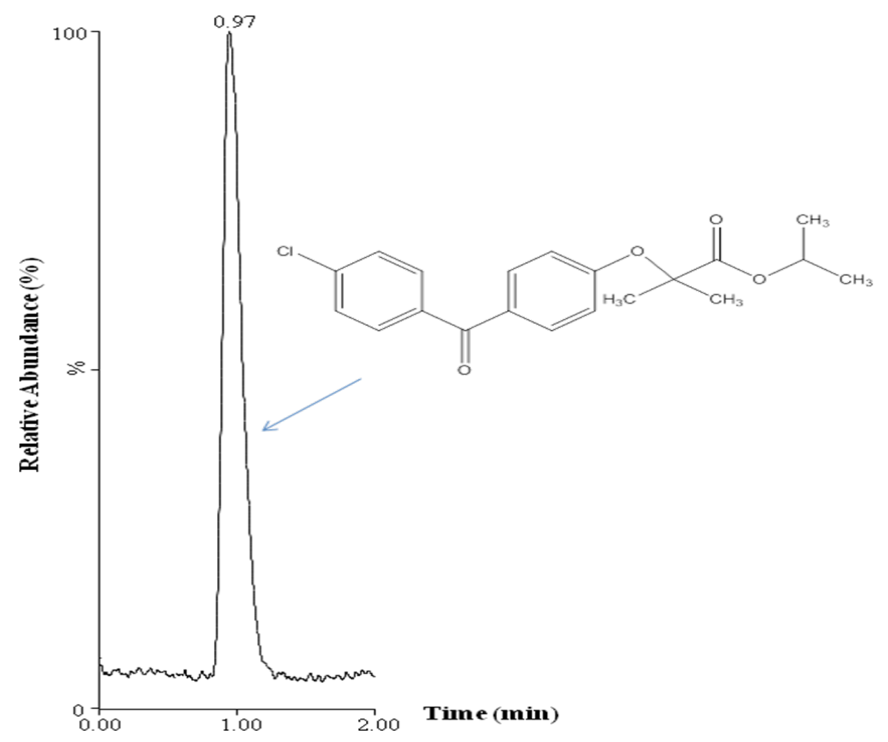

Figure 1: The peak retention time and chemical structure of fenofibrate (500ng/mL).

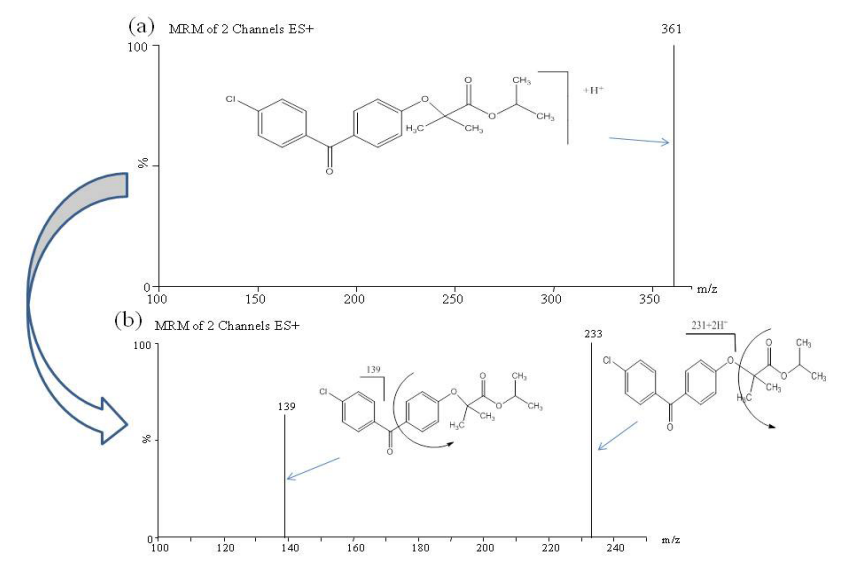

Figure 2: The (a) parent and the (b) daughter ions spectrum of fenofibrate using optimized MS parameters.

\section{Linearity}

The linearity of the developed methods was assessed by analyzing series of different concentrations $(0.1-250 \mathrm{ng} / \mathrm{mL})$ of FF solution. Under the above described experimental conditions, the calibration curve of chromatographic peak area versus FF concentration has shown good linear dynamic range. The method was linear over the concentration range of $0.5-200 \mathrm{ng} / \mathrm{ml}$ of FF. Slope, intercept, correlation coefficient $\left(\mathrm{r}^{2}\right)$, standard deviation of slope and intercept (obtained by the linear least squares treatment of the results) are listed in Table 2. The linearity was evaluated by calculation of the Relative Standard Deviation (RSD) of the slope (Sb\%) [18]. The LOD was found to be $0.12 \mathrm{ng} / \mathrm{ml}$ where as LOQ was found to be $0.41 \mathrm{ng} / \mathrm{ml}$. 


$\left.\begin{array}{|r|r|}\hline \text { Parameters } & \text { UPLC-MS/MS } \\ \hline \text { Concentration range } & 0.5-200 \text { PPB } \\ \hline \text { Intercept (a) } & 1184 \\ \hline \text { Slope (b) } & 78.102 \\ \hline \text { Correlation coefficient (r) } & 0.9932 \\ \hline \text { Standard deviation of intercept } \\ (\mathrm{Sa}) \mathrm{a}\end{array}\right)$

${ }^{a}$ mean of three measurements

${ }^{b}$ Limit of detection was estimated at a signal-to-noise ratio of 3

'Limit of quantification was estimated at a signal-to-noise ratio of 10

Table 2: Statistical data of the regression equation for the determination of FF obtained from the proposed method.

\section{Matrix effect}

According to the FDA guidelines on bioanalytical analysis, the assessment of matrix effect constitutes an important and integral part of validation for quantitative analysis of drug in plasma samples $[19,20]$. The matrix effect at three concentrations levels of FF were carried out. The mean matrix effect values for $1 \mathrm{ng} / \mathrm{mL}, 50 \mathrm{ng} / \mathrm{mL}$ and $100 \mathrm{ng} / \mathrm{mL} \mathrm{FF}$ were $(96.41 \pm 6.14) \%$, $(99.75 \pm 1.43) \%$, $(98.35 \pm 3.01) \%$. The obtained relative standard deviation was less than $3 \%$ which demonstrates the proposed method was practically free from relative matrix effects for the determination of FF in human plasma [21].

\section{Accuracy and precision}

The accuracy study was performed by addition of known amounts of FF to known concentration of the commercial tablets as well as in blank plasma (addition method). Precision of the method were assessed by intra and inter-day validation. The intra and inter-day precision were determined by determining the concentrations of spiked FF in both tablets and blank plasma in six replicates for three different concentration levels. The intra and inter-day precision were obtained by repeating the assay method three times on the same day and on three consecutive days, respectively. The repeatability of the method was expressed as the \%RSD. Accuracy was expressed as the percent deviation of the mean determined concentration against the spiked concentration. (Table 3), summarizes the mean values of accuracy and precision for both intra and inter-day assays. Both precision and accuracy results indicated satisfactory precision of the proposed methods according to the FDA guidelines.

\section{Calibration curve and LLOQ}

The calibration curves showed a good linearity in the concentration range of $0.5-200 \mathrm{ng} / \mathrm{mL}$ with correlation coefficient $\left(r^{2}>0.993\right)$. The Limit of Detection (LOD) and Limit of Quantification (LOQ) values for FF were determined according to $\mathrm{ICH}$ recommendations [22] considering the SD of the response and the slope. Limit of detection was estimated at a signal-to-noise ratio of 1:3 and limit of quantification was estimated at a signal-to-noise ratio of 1:10. The obtained results of calibration parameters are listed in Table 2.

\begin{tabular}{|r|r|r|r|}
\hline Parameters & & SD $^{\mathbf{a}}$ of peak area & \%RSD \\
\hline Precision & Intraday & 0.14 & 0.92 \\
\cline { 2 - 4 } & Interday & 0.15 & 1.32 \\
\hline \multirow{1}{*}{ Robustness } & Solvents & 1.59 & 1.22 \\
\cline { 2 - 4 } & $\begin{array}{r}\text { Mobile phase } \\
\text { composition }\end{array}$ & 1.02 & 1.66 \\
\cline { 2 - 4 } & $\begin{array}{r}\text { Column tem- } \\
\text { perature, }\end{array}$ & 0.58 & 1.25 \\
\hline & Cone voltage, & 0.44 & 1.44 \\
\cline { 2 - 4 } & Collision energy & 0.66 & 1.77 \\
\cline { 2 - 4 } & $\begin{array}{r}\text { Source tempera- } \\
\text { ture }\end{array}$ & 0.72 & 1.06 \\
\cline { 2 - 4 } & $\begin{array}{r}\text { Dessolvation } \\
\text { temperature }\end{array}$ & 0.11 & 1.11 \\
\cline { 2 - 4 } & & 0.55 & 0.98 \\
\hline
\end{tabular}

SD, standard deviation: a mean of three measurements

Table 3: Precision and robustness of proposed method was achieved using average of three different concentration levels $(1.15,50.56$ and $99.5 \mathrm{ng} / \mathrm{ml})$ of FF.

\section{Robustness}

Robustness, the measure of reliability of a method was evaluated during the development and validation of the proposed method. It was performed by small and deliberate variation of the method parameters in three different concentration levels of FF. The parameters studied were solvents, mobile phase composition, flow rate, column temperature, cone voltage, collision energy and source and dessolvation temperature. It was found that deliberate variation in the above mentioned parameters has no significant effect on FF determination using proposed method. The low RSD\% values indicated the good measure of reliability (robustness) of the developed UPLC-MS/MS method (Table 3).

\section{Application}

Determination of FF in tablet formulation: In order to assess the applicability of the UPLC-MS/MS method, the determination of FF was performed in its tablet formulations. The procedure of sample preparation was carried out as described under tablet sample preparation in the experimental section. Six replicate determinations for FF were performed. Satisfactory results were obtained in a good agreement with the label claimed. The obtained results were validated by spiking FF standards of three concentration levels to tablet samples. The recoveries were obtained in the range of $99.00-100.65 \%$ Table 4 . Figure $3 \mathrm{~b}$ shows the UPLCMS/MS chromatograms of FF in Lipanthyl ${ }^{\circledR} 200 \mathrm{M}$ tablets. The chromatograms did not show any interference, as no detectable matrix peak was eluted in the retention time of FF. Nevertheless, there are slight changes in the retention time (0.98min) of the analyzed compounds; this might be due to the matrix effect of the column.

Determination of FF in spiked human plasma: The proposed method was also employed to the analysis of plasma samples, fortified with varying amounts of FF (1-100ng/mL), after LL extraction procedure. The extraction recovery of FF was determined by measuring the mean peak area response of six replicates of extracted all three spiked samples. The mean extraction recoveries of FF were varied in the range of 92.4 - 
$-94.2 \%$. To validate this results the standard addition procedure were performed and that gives the recovery in the range of 97.3 - 99.2\% with RSD\% ranged from 1.3 to 3.1 Table 4 . Figure $3 \mathrm{a}$ and $3 \mathrm{c}$ shows the UPLC-MS/MS chromatograms of blank plasma and FF spiked human plasma samples, respectively. The chromatograms did not show any detectable matrix peak in the retention time of FF. On the other hand, slight change in the retention time $(0.98 \mathrm{~min})$ of the analyzed compound demonstrates that the proposed method was practically free from relative matrix effects for the determination of FF in human plasma. The preliminary results were shown to be consistent, precise and reproducible in spiked plasma samples and suggested that the methodology can be applied in the assay of the FF in biological fluids.
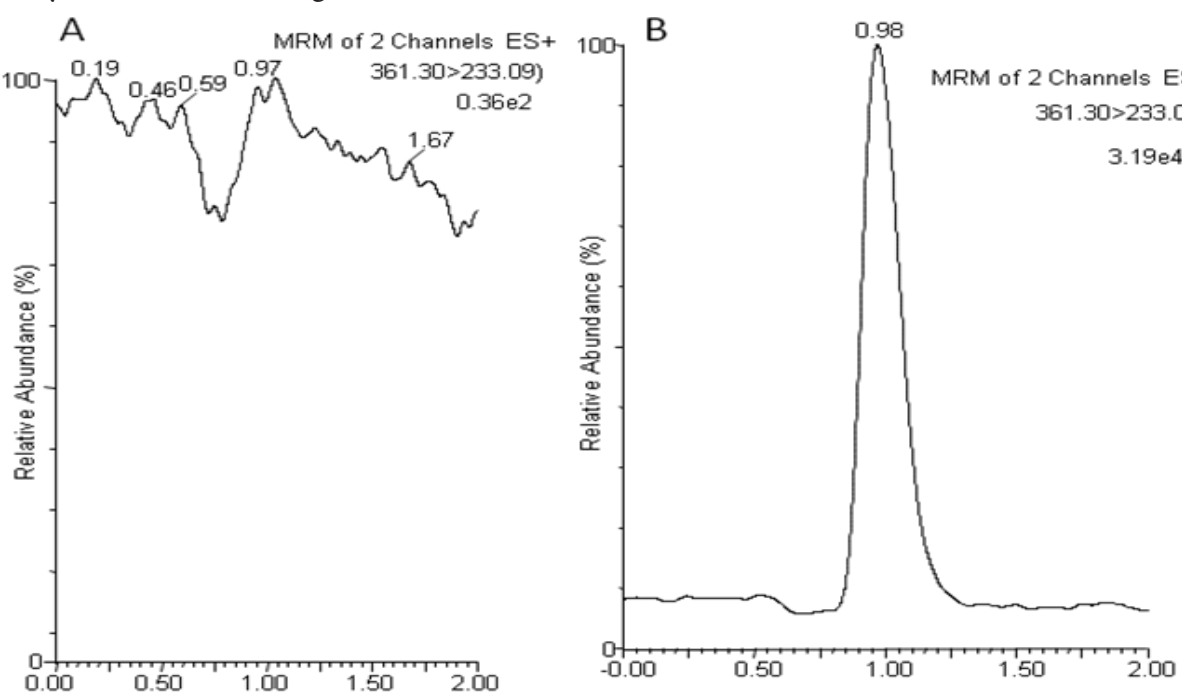

\section{Conclusion}

The present UPLC/MS-MS analytical work illustrates simple, cost effective and non interfering spectrometric method for quantification of FF in pharmaceutical dosage and plasma samples. The method has shown suitable LOQ $(0.41 \mathrm{ng} / \mathrm{mL})$ and LOD $(0.12 \mathrm{ng} / \mathrm{mL})$ along with the very short retention time of 0.97 minute. In addition, a high recovery of fenofibrate in plasma samples was recorded in the current analytical method. The method had advantage over problems of poor chromatography, questionable uncharacterized peak, tedious extraction steps, and high injection load. The method is fully validated as per FDA guidelines, is accurate, robust and

Figure 3: The MRM chromatograms of (A) blank plasma, (B) fenofibrate (100ng/mL) in tablet (lipanthyl $\left.{ }^{\star}\right)$ and (C) blank plasma spiked with fenofibrate (50ng/ $\mathrm{mL})$ using optimized MS conditions.

\begin{tabular}{|c|c|c|c|c|c|c|c|}
\hline Real sample & $\begin{array}{r}\text { Amount } \\
\text { claimed/fortified }\end{array}$ & $\begin{array}{l}\text { Found/Recover } \\
(\mathrm{ng} / \mathrm{ml}) \pm \mathrm{SDa}\end{array}$ & $\begin{array}{r}\text { Recovery } \\
(\%)\end{array}$ & Added (ng/ml) & $\begin{array}{r}\text { Found } \pm \text { SDa } \\
(\mu \mathrm{g} / \mathrm{ml})\end{array}$ & $\begin{array}{r}\text { Recovery } \\
(\%)\end{array}$ & RSD (\%) \\
\hline \multirow[t]{4}{*}{ tablet } & \multirow[t]{4}{*}{$200(\mathrm{mg} / \mathrm{tab})$} & \multirow[t]{4}{*}{$198.8 \pm 1.7(\mathrm{mg})$} & \multirow[t]{4}{*}{99.42} & 1.00 & $1.01 \pm 0.04$ & 99.00 & 4.04 \\
\hline & & & & 25.00 & $24.91 \pm 0.41$ & 99.64 & 1.66 \\
\hline & & & & 50.00 & $50.33 \pm 0.62$ & 100.65 & 1.22 \\
\hline & & & & 100.00 & $99.79 \pm 0.72$ & 99.79 & 0.72 \\
\hline \multirow{4}{*}{$\begin{array}{r}\text { Blank hu- } \\
\text { man plasma }\end{array}$} & $1.15 \mathrm{ng} / \mathrm{ml}$ & 4.14 & 100.33 & $1.00 \pm 0.04$ & 1.00 & 92.46 & $1.06 \pm 0.04$ \\
\hline & $20.44 \mathrm{ng} / \mathrm{ml}$ & 3.70 & 97.52 & $24.38 \pm 0.90$ & 25.00 & 93.18 & $19.04 \pm 0.30$ \\
\hline & $50.56 \mathrm{ng} / \mathrm{ml}$ & 1.21 & 96.18 & $48.09 \pm 0.58$ & 50.00 & 94.00 & $47.52 \pm 0.51$ \\
\hline & $99.50 \mathrm{ng} / \mathrm{ml}$ & 1.44 & 96.08 & $96.08 \pm 1.38$ & 100.00 & 94.22 & $93.75 \pm 0.79$ \\
\hline
\end{tabular}

SD, standard deviation: ${ }^{a}$ mean of three measurements

Table 4: Recovery study of FF in spiked and added plasma and tablet samples.

reproducible. As the pace of drug development quickens, we cannot ignore the potential for our method application not only the time savings but it can present encouraging clinical and exploratory studies for the best possible lipid regulating agents. The results of the quality parameters, analysis time and resolution achieved with this system confirm the established UPLC-MS/MS method can be successfully applied to the determination of fenofibrate in the Pharmaceutical tablet formulation and human plasma samples.

\section{Acknowledgement}

Authors are grateful to the Research Centre of the college of Pharmacy and the Deanship of the Scientific Research of the King Saud University for their funding and support.

\section{References}

1. Neil MJO (2001) The Merck Index. Merck Research Laboratories, NJ, USA.

2. USP/NF (2009) The official compendia of standards. 2: 2351-2354. 
3. Tripathi KD (2004) Essentials of medical pharmacology. (5th edn) Jaypee Brothers Publications, Delhi, India.

4. Council of Europe (2008) European pharmacopoeia. (6th edn) Directorate for the Quality of Medicines, Strasbourg, France 2: 1875-1876.

5. Dubey SK, Tomar MS, Patni AK, Khuroo A, Reyar S, et al. (2010) Rapid, sensitive and validated ultra performance liquid chromatography/mass spectrometric method for the determination of fenofibric acid and its application to human pharmacokinetic study. e-journal of chemistry 7: 25-36.

6. Madureira TV, Rocha MJ, Cass QB, Tiritan ME (2010) Development and optimization of a HPLC-DAD method for the determination of diverse pharmaceuticals in estuarine surface waters. J Chromatogr Sci 48: 176-182.

7. Straka RJ, Burkhardt RT, Fisher JE (2007) Determination of fenofibric acid concentrations by HPLC after anion exchange solid-phase extraction from human serum. Ther Drug Monit 29: 197-202.

8. Lacroix PM, Dawson BA, Sears RW, Black DB, Cyr TD, et al. (1998) Fenofibrate raw materials: HPLC methods for assay and purity and an NMR method for purity. J Pharm Biomed Anal 18: 383-402.

9. Kadav AA, Vora DN (2008) Stability indicating UPLC method for simultaneous determination of atorvastatin, fenofibrate and their degradation products in tablets. J Pharm Biomed Anal 48: 120-126.

10. Hernando MD, Petrovic M, Fernández-Alba AR, Barceló D (2004) Analysis by liquid chromatography-electrospray ionization tandem mass spectrometry and acute toxicity evaluation for beta-blockers and lipid-regulating agents in wastewater samples. J Chromatogr A 1046: 133-140.

11. Vazquez-Roig P, Segarra R, Blasco C, Andreu V, Picó Y (2010) Determination of pharmaceuticals in soils and sediments by pressurized liquid extraction and liquid chromatography tandem mass spectrometry. J Chromatogr A 1217: 2471-2483.

12. Korany MA, Hewala II, Abdel-Hay KM (2008) Determination of etofibrate, fenofibrate, and atorvastatin in pharmaceutical preparations and plasma using differential pulse polarographic and square wave voltammetric techniques. J AOAC Int 91: 1051-1058.

13. Yardimci C, Ozaltin N (2004) Electrochemical studies and square-wave voltammetric determination of fenofibrate in pharmaceutical formulations. Anal Bioanal Chem 378: 495-498.
14. Dhabale PN, Gharge DS (2010) Simultaneous spectrophotometric estimation of atorvastatin and fenofibrate in bulk drug band dosage form International Journal of Chem Tech Research 2: 325-328.

15. Gupta KR, Askarkar SS, Rathod PR, Wadodkar SG (2010) Validated spectrophotometric determination of fenofibrate in formulation. Pelagia Research Library Der Pharmacia Sinica 1: 173-178.

16. Nagaraj, Vipul K, Rajshree M (2007) Simultaneous quantitative resolution of atorvastatin calcium and fenofibrate in pharmaceutical preparation by using derivative ratio spectrophotometry and chemometric calibrations. Anal Sci 23: 445-451.

17. Salama FMM, Nassar MWI, Sharaf El-Din MMK, Attia KAM, Kaddah MY (2011) Determination of Fenofibrate and the Degradation Product Using Simultaneous UV-Derivative Spectrometric Method and HPLC. American Journal of Analytical Chemistry 2: 332-343.

18. Torrado S, Torrado S, Cadorniga R (1994) Comparison of assay methods by second-derivative spectroscopy, colorimetry and fluorescence spectroscopy of salicylic acid in aspirin preparations with a high-performance liquid chromatographic method. J Pharm Biomed Anal 12: 383-387.

19. Matuszewski BK, Constanzer M, Chavez-Eng CM (2003) Strategies for the assessment of matrix effect in quantitative bioanalytical methods based on HPLC-MS/MS. Anal Chem 75: 3019-3030.

20. Guidance for Industry (2001) Bioanalytical Method Validation, U.S Department of Health and Human Services, Food and Drug Administration.

21. Matuszewski BK (2006) Standard line slopes as a measure of a relative matrix effect in quantitative HPLC-MS bioanalysis. J Chromatogr B Analyt Technol Biomed Life Sci 830: 293-300.

22. Q2A, ICH, Q2A (R1) (2005) Validation of Analytical Procedures: Text and Methodology, International Conference on Harmonisation, Geneva, Switzerland.

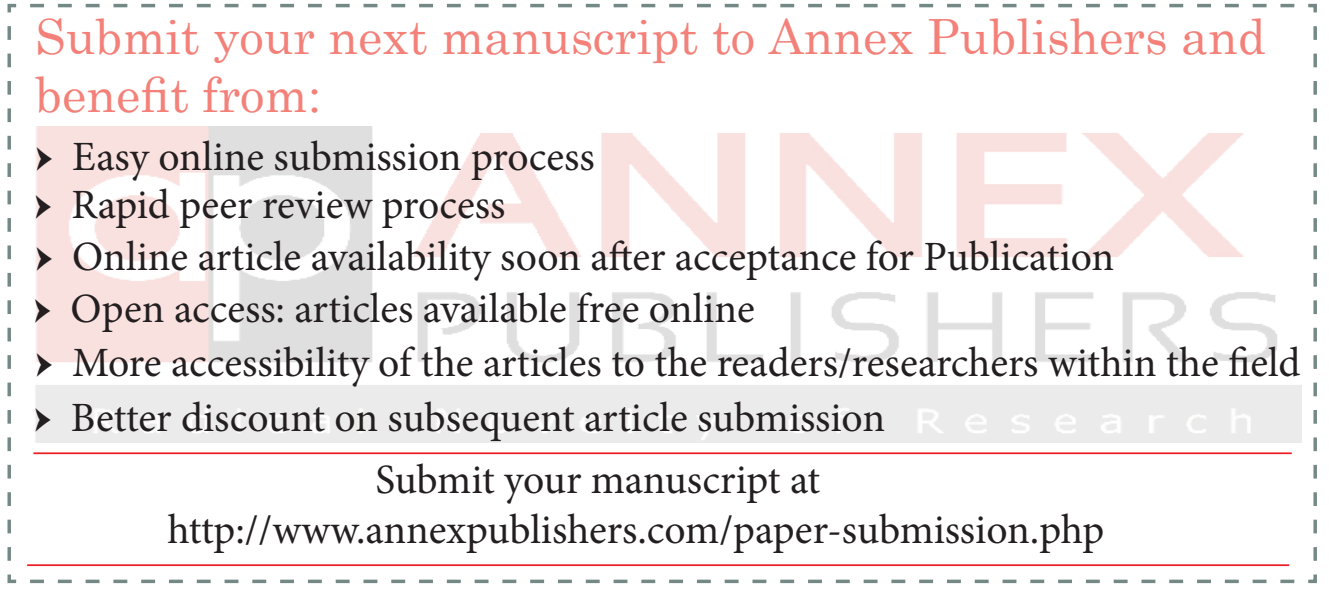

